\title{
The Weights and Measures of India.
}

By C. A. Silberrad, President Indian Weights and Measures Committee.

\begin{abstract}
A COMMITTEE was appointed by the Government of India in the autumn of I9r 3 " to inquire into the whole question of the feasibility of securing the use of uniform weights and measures in India." It submitted its report ${ }^{1}$ in July I9I4, but further consideration of the matter was delayed by the war and subsequent political developments in India, and it was only in April ro22 that, after consultation with Local Governments, the final resolution on the report was issued. This in brief approved the recommendations of the report and left it to Local Governments to give effect to them so far as and in what way each
\end{abstract} thought advisable.

Like its inhabitants, the weights and measures of India are extremely diversified; but, like them, they are susceptible of a certain amount of classification. Doubtless originally the systems which came into use at the different centres were entirely independent, but with the centralisation of administration, the unification of the coinage, and the spread of railways a certain degree of systematisation has arisen, and the weight of the tola has been assimilated to that of the rupee (I8o grains), and is recognised practically everywhere as a fundamental unit, the relation of which to almost all weights in actual use is known.

The system of weights most widely known is that in force on the railways. This consists of the seer of 80 tolas (of I 80 grains each) and the maund of 40 seers, with the chatak of 5 tolas. This system is used almost to the exclusion of any other in the west of the United Provinces, the Panjab, except a tract in the centre and the districts bordering on the North-west Frontier Province, the Hazara district of the latter, Sind, Baluchistan, the north of the Bombay Deccan, and the greater part of the Central Provinces. In the Central Panjab, the southern portions of the United Provinces, Chota Nagpur, and practically all Bengal and Assam this system is in use in combination with various other seers-usually known as kachchha (i.e. imperfect) seers, consisting of a variable but always smaller number of tolas-usually 40 to 60 . In Rohilkhand (United Provinces) and the western Panjab with the trans-Indus portion of the Frontier Province the most usual system is one in which the seer contains about roo tolas, while in Gujarat that most commonly used contains 40 tolas.

In the eastern parts of the United Provinces and the greater part of Behar proper, with adjoining portions of Chota Nagpur, the popular systems are extraordinarily variable. They are based on some number of gandas (sets of four) of the local pice (copper coins). These are of two kinds-Gorakhpuri and Lohiya. The Gorakhpuri pice were coined at Butwal in Nepal, and like Lohiya pice consist of shapeless dumps of copper, the weight of which was variable when they were new, and has become much more so with use. A number of gandas of such pice was taken to represent the seer of the place concerned. That number would naturally represent a somewhat different weight when other pice were used, so some would be added or subtracted, and that new number would start a new seer. Matters were further complicated by the adoption of the rupee in some places as unit instead of the local pice, the same numbers being used. The numbers supposed to be equivalent to a definite weight vary considerably, a fair average is Ioo Lohiya pice $=92$ Gorakhpuri pice $=80$ tolas. In the Gorakhpur district seers of $8,8 \frac{1}{2}$, II, I2, I3, I Report of the Weights and Measures Committee, published by the Government of India. Government Central Press, Simla. Rs.
I $3 \frac{1}{2}, I_{3} \frac{3}{4}, I 4,2 I, 22,24 \frac{3}{4}, 25,27,27 \frac{1}{2}, 28,32,36$, and 40 gandas of such pice are reported, while with other seers the total number reported as in use in various parts of the district amounts to 42 , not to mention several panseris (literally five seers) weights to which there is no corresponding seer in use. The Lohiya pice are fully as variable; I2I separate gandas when weighed were found to give 60 different weights varying from $53 \mathrm{I}$ to 675 grains. The result is extraordinary confusion.

The kachchha seer of 32 to 36 tolas used in the central Panjab has a somewhat similar origin, this seer being supposed to be the weight of 36 mansuri pice, a coin coined in the Maler-Kotla state and of varying weight, the 36 averaging $33 \frac{1}{3}$ tolas. Similarly in the northwest Frontier Province the Peshawari seer was supposed to be the weight of 102 Doadzashahi or Nanakshahi rupees, each of which was slightly heavier than the present rupee.

Lastly, there are the tracts where a small seer of is to 28 tolas is used to the more or less complete exclusion of any other seers. Thus in Bombay city the ordinarily used seer is of 28 tolas, and small seers of something near this weight are current throughout the southern Bombay Deccan, the Konkan, and west Berar.

Throughout these parts of India the table of weights is very similar. The chatak is always one-sixteenth of the seer; it is, however, known by other namese.g. it is a kanwa in parts of Behar and Orissa, a sharak in the western Panjab, and an anna in Sind; while the sixteenth part of the central Panjab kachchha seer is termed a sirsai. In some tracts the chatak is divided into four parts; these are termed kachha in Bengal and duko in Sind.

The maund, though usually containing 40 seers, does not do so by any means always, the variations in this respect being by commodities as well as by localities. Thus in Cawnpore a dozen different maunds, containing from $4 \mathrm{I}$ to 63 seers (of 80 tolas), are in use for various kinds of merchandise, and in Bombay city seven maunds and 12 khandis. This latter is a weight supposed normally to contain 20 maunds, those in use in Bombay vary from ii to 28 Bombay maunds (of 40 seers each of 28 tolas).

So far as they fall into this classification the Madras weights come under this head, as the standard seer for Madras contains 24 tolas and the larger seers are but little used, though the 80-tola seer is known through its use on the railways and by Government. The standard table is 3 tolas $=$ one palam ; 8 palams $=$ one seer; 5 seers =one viss; 8 viss =one maund. But the palam is 6 tolas in Madras, varies from $3 \frac{3}{8}$ to I5 in Malabar, and is $\frac{1}{4}$ th pound avoirdupois in Tinnevelly. The viss too may sometimes be 6 seers, and maunds and khandis (usually 20 maunds) vary as greatly here as elsewhere. Certain places have other peculiar weights-e.g. the thukku, varying from 100 to 250 tolas, and the tulam from 800 to 1350. An interesting survival is the use of the Dutch pound (termed rathal and deemed equivalent to $42 \frac{1}{2}$ tolas) in Cochin. Similarly the British pound has given rise to a rathal of $38 \%$ tolas, and in the parts of Arcot near Pondicherry the half-kilo to one of 42.9 tolas. The Madras weights are the most confused and complicated of all India, this being due possibly to the greater differences between the peoples composing its population, and to the fact that much of the Presidency never formed part of the Mughal Empire, and that consequently the basis of many of the weights was not the rupee but the pagoda or some
blishing Group 
other coin, so that the adoption of the rupee tola as a unit was more difficult.

The following table, showing the number of different seers reported to the Weights and Measures Committee in I9I3-I4 in each province, will give perhaps a clearer idea of the complexity and confusion of Indian weights than anything else :

\begin{tabular}{|c|c|c|c|c|c|c|c|c|}
\hline \multirow[b]{2}{*}{ Province. } & \multicolumn{7}{|c|}{ Number of Seers equivalent to } & \multirow{2}{*}{$\begin{array}{l}\text { Weights in } \\
\text { Tolas of } \\
\text { smallest and } \\
\text { largest Seer. }\end{array}$} \\
\hline & $\begin{array}{c}\text { Less } \\
\text { than } 30 \\
\text { Tolas. }\end{array}$ & $\begin{array}{c}30- \\
50 .\end{array}$ & $\begin{array}{c}50- \\
70 .\end{array}$ & $\begin{array}{c}70- \\
90 .\end{array}$ & $\begin{array}{l}90- \\
\text { 110. }\end{array}$ & $\begin{array}{c}\text { Above } \\
\text { IIO. }\end{array}$ & Total. & \\
\hline United Provinces. & 4 & $2 \mathrm{I}$ & II & 24 & 30 & $I_{3}$ & Iо6 & I $8 \ddot{z}-130$ \\
\hline Bengal : . & $\stackrel{4}{1}$ & . & 7 & $\begin{array}{l}24 \\
19\end{array}$ & I0 & 6 & 43 & $16-189$ \\
\hline Madras: : & 12 & 2 &.. & $x_{3}$ & 2 & .. & 29 & $20-105$ \\
\hline Behar and Orissa . & $\mathrm{I}$ & 18 & 12 & I6 & 8 & 3 & 58 & $28-132$ \\
\hline Panjab. & .. & 15 & .. & 4 & 8 & .. & 27 & $30-105$ \\
\hline Bombay : . & I5 & 5 & I & 5 & .. & 2 & 28 & I5-130 \\
\hline Central Provinces . & 3 & 2 & $\mathrm{I}$ & 2 & 3 & .. & II & $2 I-100$ \\
\hline Assam . . . & .. & .. & 2 & 6 & 4 & 2 & I4 & $60-120$ \\
\hline N.-W. Frontier Province & .. & $\ldots$ & I & 3 & 4 & 2 & 10 & $50-154 \frac{1}{3}$ \\
\hline Baluchistan . . & .. & .. & . & 1 & $\ldots$ & .. & I & $80^{2+3}$ \\
\hline
\end{tabular}

but little effect outside a few of the municipalities. It varies slightly, having apparently originally been really about $I_{42} \frac{6}{7}$ tolas, and was formerly held to be equivalent to $3.65 \mathrm{lbs}$. avoirdupois (or $\mathrm{I}_{4} \mathrm{I}_{1} \frac{7}{8}$ tolas). The peiktha is divided into roo kyat or gyat, known to Europeans as tikal. This, it may be mentioned, is, so far as 1 know, the only truly decimal subdivision current anywhere in the Indian Empire.

For weights below the tikal the original table appears to have been 2 small ywès $=$ one large ywè ; 2 large ywès $=$ one pè $; 2$ pès $=$ one mú; 5 pès $=$ one mat; 2 mats or 5 mús $=$ one ngá-mú (" five-mú ") ; 2 ngá-mú =one tikal. Various seeds are used to represent some of these weights; thus, that of the Abrus precatorius is held to be equal to the small, and that of the Adenanthera pavonina to the large ywè. while the seed of the Garcinia pedunculata is occasionally deemed equal to 8 large ywès. This table was com-

Weights smaller than the tola are used mainly by jewellers and physicians, and the most fundamental unit for these throughout India would appear to have been originally the red and black seed of the Abrus precatorius, termed in Northern India the gunchi, and assumed to weigh one ratti. Other seeds and grains were also used, such as the poppy seed, the seed of the Casalpinia sepiaria and grains of juar (the greater millet), rice, wheat, and barley. The tola used in this table frequently differs from that of I8o grains, but is now usually connected therewith by being deemed equal to a definite number of rattis more (or less) than the standard tola. A very usual table in Northern India is-8 khaskhas (poppy seeds) $=$ one chawal (grain of unhusked rice); 2 chawal= one jau. (barleycorn); 4 jau $=$ one ratti ; 8 rattis $=$ one masha; and I2 mashas=one tola. In Bengal, Behar, and Assam the dhan (grain of husked rice) takes the place of the jau. In Bombay and the Central Provinces 2 rattis make a val, which is held to be represented by the seed of the Casalpinia sepiaria, while in part of the Chanda district a grain of wheat serves this purpose. Throughout Behar, Bengal, Assam, and the greater part of the Central Provinces the jewellers' tola is usually I8o grains. In Northern India it is usually greater by from one to twelve rattis, the most usual values being two, three, or four rattis in excess. Occasionally, however, the gold tola is less than 180 grains. In Bombay it varies from I 72 to 192 grains. In Madras jewellers' weights seem to vary almost from district to district, and the complications are innumerable. The seed of the Abrus precatorius, held to represent the weight gundumani or guruginja, is a frequent unit, but various obsolete coins (e.g. the fanam and the pagoda) and their fractions are in use, and the relations of these weights to the I8o-grain tola usually but little known. As an example of the result of these multifarious measures it may be mentioned that silver is occasionally weighed in Madras by a table which is connected with the standard tola by the fact that 3399 of the rattis thereof are equal to 64 tolas! As a matter of fact, throughout India current silver coins are largely used as weights, though the larger jewellers frequently have well-made sets of weights representing the locally current table.

There remains Burma. The weights of this province though showing some connexion with those of Madras, are fundamentally different. The universally current unit is the peiktha, usually known to Europeans by its Madras name of viss, which has been fixed by Government as I40 tolas (3.60 lbs. avoirdupois), though as a matter of fact this " fixation " has had NO. 2757 , vOL. I IO] plicated by the fact that, owing to intercourse with India, the tikal was divided also into I6 parts, equally known as $p \grave{e}$, and then four of these went to the mat. Further complications were introduced by the application of the same series of subdivisions to the tola of 180 grains, as fundamental unit, in place of the tikal, while in the Ruby Mines district the ratti is thus subdivided. The result, needless to say, is extreme confusion.

British (avoirdupois) weights are a good deal used in Bombay city and some of the big towns of Bombay, Berar, and the west of the Central Provinces, and in a considerable number of places in Madras, but practically only in large places and by the larger establishments. Not infrequently the nearness of the pound weight ( $39 \frac{8}{9}$ tolas) to the half of the 80 or the whole of the 40 tola seer leads to mistakes, or even to deliberate fraud. Any knowledge of the metric system is confined practically to the neighbourhood of Pondicherry.

Only the more important variations have been discussed; to give anything lilke a complete list would be far beyond the limits of space admissible. The Weights and Measures Committee of I9I3-I4 prepared a complete list showing for each district in India and Burma all weights and measures reported to them as in use. It forms a volume of some 500 pages. Enough has, however, been said to show the extreme confusion in weights that exists in many parts of India.

Apart from the use of seeds to represent weights there are few items of special interest. In Upper Burma before the annexation, weights based on the system sanctioned by the King were always made in the form of the hentha (known in India as the Brahmini duck). Although in many parts of India well or fairly well made metal weights are in use, often the actual weights consist of lumps of metal or stone, while smaller weights are made out of buttons, etc. Even where cast-iron weights are in use it will frequently happen that there is no indication as to the precise seer, etc., which is deemed to be represented. Thus two or more iron seers of identical appearance but different weights may be found in use in the same town, and sometimes even in the same shop.

In a few places, and these by no means the more advanced, locally made steelyards are used; thus in Cuttack the bisa is a steelyard with movable fulcrum used to weigh articles up to 4 or 5 pounds. Similar steelyards, called tul or tulachoni, are in use in several districts in the Brahmaputra valley. In Burma, steelyards with fixed fulcrum (known as le-dan or Pubing-tzu are regularly used by the Chinese, but 
looked askance at by the Burmans, who sometimes find themselves outwitted by the Chinaman when it is used. This instrument, frequently well made of bone or ivory, has one movable weight and two or three points of support, with scales marked on the rod corresponding to each point of support.

Measures of Length.-As almost throughout the world the cubit, or distance from the elbow to the tip of the middle-finger, was the original fundamental unit. This is subdivided into spans, fist-breadths, and digits, and also into sixteenths. A very usual table in Northern India is : 3 jau (barleycorns) $=$ one angul (digit); 3 angul =one girha ; 4 angul =one mushti (fist-breadth); 4 girha or 3 mushti =one balisht (span) ; 2 balisht = one hath (cubit) ; 2 hath $=$ one gaz (yard).

The names of the various measures of length naturally vary in different parts of the country; thus the yard is a val, var, or war in Bombay and the Central Provinces, and a gaik in Burma; the cubit, known as hath throughout Northern India, is a mura or mulam in parts of Madras and a taung in Burma. The girha is a visam in Madras, but corresponds to no measure in Burma. The balisht of Northern India is the bighat of Bengal, the jana of parts of Madras, and the htwa of Burma; but the general table is very similar throughout the whole country. The gaz (gaj, var, or gaik) varies considerably from place to place, and for different articles, and altogether the number of variants is great; the great majority, however, are within three inches of the British yard, but there are yards in use as long as $48 \mathrm{in}$. and as short as 19 in., but such are exceptional. To a greater or less extent all are being assimilated to the British yard of 36 in., and in fact many are known by their length in sixteenths (girha) of that measure. The foot and inch are but little known, the yard being almost always subdivided, for practical purposes, into I6 girha.

The most important of other yards are :

(i.) That based on the murwan or morni (crooked) hath of approximately 24 in. This cubit was arrived at by measuring from the elbow round the tip of the outstretched middle-finger and back to the knuckle; it gives rise to a yard of 40 in. to 48 in., and the British yard is deemed equal to $\mathrm{I}_{2}^{\frac{1}{2}}$ morni hath. It is in use in several districts of the Panjab near the Indus and the adjacent parts of the Frontier Province. It is divided into sixteenths (known as sharak or tasu) and also into twentieths, which are called girha.

(ii.) The Peshawari yard of 38 in. to $38 \frac{3}{4}$ in., of which the British yard is deemed to be 15 girhas (i.e. $1 \frac{5}{6}$ ths). It is used throughout most of the Frontier Province.

(iii.) The Imarati or Mi'mari gaz (masons' or carpenters' yard). It is still used fairly widely in the north-western part of the United Provinces and the adjacent parts of the Panjab. Its usual length is 33 in., and it varies from $32 \frac{1}{2}$ in. to 34 in. It forms part of a special table used in the building and carpentry trades. This is : 4 pain (or 2 sole) $=$ one sut; 4 sut $=$ one pan ; 4 pan =I tasu; 24 tasu=one imarati gaz. This table is however sometimes applied to the British yard, giving rise to a tasu of exactly $\mathrm{I}_{2} \frac{1}{2}$ in. This yard is probably identical with the tachumulam of the southern districts of Madras, which is 33 in. in length and used by carpenters and masons only. In the South Arcot district there is also a special "architectural inch" of $\mathrm{I}_{\frac{1}{4}}$ in. British, 24 of which make the " architectural yard." In Bombay city yards of 32 and 24 tasu are occasionally used for measuring cloth, this tasu is $1 \frac{1}{8}$ in. British measure. Beyond the similarity of names of the subdivisions there would appear to be no connection.

(iv.) The Ilahi or Akbari gaz, originated by Akbar to represent one pace for purposes of land 1922 Nature- ment, and at first $33 \frac{1}{2} \mathrm{in}$. in length, but now varying from $3 \mathrm{I} \frac{1}{2}$ in. to $40 \mathrm{in}$. It is over much of Northern India the basis of many indigenous systems of land measurement.

On the Malabar coast the yard is to some extent replaced by the kole, a measure of similar length, which consists of 24, or in places of $26 \frac{1}{2}$, angulams (or virals), which appear to be the length instead of the breadth of a finger joint, inasmuch as one angulam is held exactly to equal the diameter of a rupee or $I_{6}^{1}$ in.

Apart from the measures used for measuring land and distance there are practically no measures of any importance larger than the yard. Those for land measurement are closely connected with measures of area and will be considered therewith. Measurements of distance are usually vague. The normal indigenous unit is the kos (or in Madras the kros). Though supposed to be 4000 cubits it really has little, if any, connexion with that unit and varies from $I \frac{1}{2}$ to 3 miles. The corresponding unit in Burma is the daing or taing, supposed to contain 7000 cubits, but in reality equally vague. With the construction of roads and railways and the indication of miles and furlongs thereupon, these measures are now almost universally known and used. A somewhat unfortunate complication has, however, been introduced into the Panjab by the invention of a Canal " mile" of 5000 feet divided into five equal parts, each of which (from the shape of the " $\frac{1}{3}$ th-milestone" or burj) is termed a burji. Somewhat interesting is the introduction of new measures of length by reason of the way in which land is subdivided in the Canal colonies into marabbas (squares) and killas of I I oo ft. and $220 \mathrm{ft}$. square respectively. The lengths of the sides of these square areas are becoming known as measures of length under the names of the areas.

Most frequently however distances are referred to by the average villager as "the length of a field," "a gunshot," " the distance to which a man's voice will carry," etc.

Measures of Area. - There can be little doubt that the first measures of area depended on the amount of work involved in cultivating the area concerned, or the amount of seed required to sow, or produced by it. Thus the bigah, the most widespread unit of area, is said to have originally represented the area a pair of bullocks could plough in a day. Other units are defined as the area a pair of animals could maintain under cultivation throughout a year, or that they can harrow or sow in a day, or that a man can weed in a day. Many units are based on the area sown with some stated quantity of seed; in rice-growing areas by the number of paddy plants required for planting it, or as the area which a man (or sometimes a woman) can plant in a day, and so on. Another measure used in some parts is the area which can be guarded from the depredations of wild animals by one watchman on a raised platform. In Baluchistan a common measure of land is the area which can be irrigated in 24 hours.

These methods of estimating areas are still widely used by the cultivators themselves in the less thickly populated areas, such as most of the Central Provinces, Burma and Chota Nagpur, and parts of Bombay, Madras and Assam and the Himalayan tracts.

In the more densely populated parts of the country, where the value of the land is greater, a more definite method has been evolved. This throughout almost the whole of both India and Burma seems to have been based on a square each side of which is a certain number of paces, but which is now always expressed in terms of cubits. The length of this unit is extremely variable, but it would appear that in selecting a length the simplest that could be expressed conveniently in both cubits and paces was originally taken. Thus many of these units are near to 5 
cubits, which, taking the cubit at 18 in., is equal to three paces of 33 in. each. This unit length has many names: in the United Provinces it is termed a latta or gatha, and the standard (so far as there was one) was three Akbari gaz (of $33 \frac{1}{2}$ in. each). The standard most often recognised by Government, however, is of 99 in., so that 20 equal a chain of 55 yards. In the Panjab, the Frontier Province, and Sind the corresponding unit is the karam, the most important one being 66 in. in length. In Behar and Orissa it is known as the bans, lagga, padika, or nal, and usually varies between $6 \mathrm{ft}$. and I $2 \mathrm{ft}$. In Bengal it is a dhau, danda, nal, or katha. In Assam a nal, tar, or bes. In Bombay proper a kathi, and in Sind a kano; in Madras a nolo (Ganjam) or badda (Nellore), and in Burma a $t a$ (" $=$ seven cubits or $10 \frac{1}{2} \mathrm{ft}$.). The actual area arrived at by this method is, however, most variable, and though the unit length seems to have originally been about three paces it may, as a matter of fact, be apparently anything from one to five. The more valuable the land and the more powerful the landowner the smaller is the laggi. A not infrequent method of raising rents was to shorten the length of the laggi, the " rent per bigah " remaining nominally the same for the smaller resultant bigah. Many riots have been caused by differences of opinion between landlord and tenant as to the correct length of the laggi. The square laggi has many names: in the United Provinces it is usually a biswansi, in the Panjab a sirsahi, in Behar a dhur, in Bombay a kathi, Assam a rekh, Burma a palagwet, and so on. Though it is almost always the four-hundredth part of the bigah (or corresponding unit), the intermediate subdivisions vary. The most general intervening unit is one consisting of 20 square laggis, known most widely as a biswa or katha (" cotta "). But in Orissa I6 of the smallest units make a guntha, and 25 gunthas go to the man (which corresponds to the bigah elsewhere). In the Panjab, where the square karam is known as the sirsahi, 9 of them go to the marla, 20 marlas equal one kanál, and 4 kanáls one bigah. Here two bigahs make a ghumaon, which has been standardised as one acre. This table holds over the western Panjab, Sind, and the Frontier Province. In Burma there are two large units-the pègadi (or "public" pè) containing 625 square ta (or palagwet), and the min-pè of 35 ta $2 \frac{1}{2}$ taung square or $1250 \frac{25}{196}$ palagwet, treated for practical purposes as exactly equal to two pègadi.

In eastern Bengal the unit length is often used somewhat differently, the unit area being sometimes rectangular. Thus in Dacca and Maimansingh a common unit is the káni, a variable rectangle, but most frequently one the sides of which are 12 and Io nal. The pakhi, another frequently used unit, appears to be practically only another name for the kani.

Though the system is so similar throughout the country it has not resulted in any uniformity; in fact, the bigah and connected measures are almost as indefinite as the older measures previously mentioned. Thus in the United Provinces no less than 58 bigahs, varying from ${ }_{1}^{1}$ th to one acre, are reported. In Champaran district (Behar and Orissa) the laggi varies from Io $\mathrm{ft}$. Io $\frac{1}{2}$ in. to $17 \mathrm{ft} .5 \frac{1}{2}$ in. In Dacca the Settlement Officer had to prepare more than roo conversion tables to reduce the local measures of area to the acre. In much of Madras the indigenous systems appear to have had other origins; thus in Madras city the cawnie of 1.32 acres is still used-this is equal to 20 manai or " grounds," the manai having originally been defined as the area sufficient for a small Indian house. Elsewhere the gorru, a measure based on the area a pair of bullocks can plough, is used; it is about $3 \frac{1}{8}$ to 4 acres.

There are numerous other units of area in use in various parts of the country, and the variations of those bearing the same name are almost innumerable, but there would seem to be little purpose in giving further details.

When precision is necessary in dealing with areas which are of such vital importance to rent law and the land revenue, two methods have been adopted. Either the bigah has been standardised over a certain area or else the British acre (divided either into roods and poles, or more usually into one-hundredths) has been used. The number of different "standardised " bigahs actually adopted in the Settlement records is very great; thus in the Gorakhpur district of the United Provinces no less than nine were used. In many parts of the country the acre and its hundredth parts (generally termed " decimals," or in Burma "dathama ") are becoming well known. In the Panjab Canal colonies two new units have been introduced - the killa of $220 \mathrm{ft}$. square and the marabba (square) of I Ioo $\mathrm{ft}$. square, equal to 25 killa, being respectively equivalent to Io and $25^{\circ}$ acres. In short, for all purposes where exactness is required either the acre and its subdivisions or some standardised indigenous measure is now used.

Measures of Capacity. - Contrary to what is sometimes alleged, measures of capacity for grain and such like articles are very widely used throughout India, the only tracts where they are practically nonexistent being the greater part of the United Privinces (excluding the extreme east and south-west), most of Behar proper, and the eastern Panjab. It is true that in much of the rest of India they are mainly used in rural areas and the smaller towns and for retail and local transactions, but even so their use is widespread and certainly affects the great bulk of the people. In Burma, and to a less extent in Madras, they are of universal importance, forming the basis of large transactions. For some reason, or possibly by pure coincidence, their use is more widespread in the rice- growing areas, though by no means excluded from the rest of the country.

The unit measure of the series in use is usually defined as a measure containing a certain number of the chief current local unit of weight of the predominant grain. Sometimes a definite weight of a mixture of several (8 or 9) kinds of grain was used to fix the size. A picturesque variant to this rule occurs in the Khasia and Jaintia hills (the inhabitants of which were head hunters), where the size of the standard measure was fixed as being convenient to hold a man's head. Measures are generally used " heaped," rarely (though occasionally) "struck." As there is no uniformity in the cross-section of measures supposed to contain equal quantities this increases the variations. The measures themselves are made sometimes of wicker-work, at others of wood or metal, and may be cylindrical, rectangular, prismoidal, hemispherical, or more or less globulari.e. in the shape of a sphere with considerably less than the upper hemisphere removed. The wicker measures especially are liable to increase in size with age. Save in Burma, Madras, and a few of the larger municipalities in the Central Provinces and Berar, no attempt has ever been made to standardise them, and there has never been anything corresponding to the unifying influence of the railway seer to assimilate the measures of different places.

The chief measure of a place is generally one containing from one to five local seers of some grain, and there are various multiples and submultiples of this, the larger ones being merely measures of account. It has already been seen how numerous are the local units of weight-the reasons just given make those of capacity even more variable. The units themselves, and the names and mutual relations of their multiples 
and submultiples, vary from district to district, and, indeed, are very far from being uniform throughout a district. As their use is largely confined to local transactions this variation is of less importance, for the normal customers of each market are fully aware of the measures in use there. It would be of little interest to give the innumerable names of these measures; one example of their variability will suffice. The gauni is a widely used measure in Orissa; the Balasore district reports the use of 18 different gaunis, said to contain anything from $\mathbf{I}$ to over 8 seers of paddy. In Cuttack its limits are somewhat closer-I $\frac{3}{4}$ to 7 seers-while in Puri they are said to be from 2 to 8 , and 9 different gaunis are reported as in use. The actual measure is made of wicker.

The standardised measures of Madras and Burma call for more detailed comment. In Madras there are two, known respectively as the Madras type measure or padi and the Madras type seer; they are defined as holding respectively $\mathrm{I} 2 \mathrm{O}$ and 80 tolas of second sort rice when "struck" or I32 and 88 when "heaped." Of water they contain 62.5 and $4 \mathrm{I} \cdot 7 \mathrm{oz}$. One or other is used throughout a considerable portion of the Madras Presidency, but by no means to the exclusion of numerous other measures which may or may not bear a definite relationship to them.

It is, however, in Burma that capacity measures are of greatest importance, as it is by the tin or "basket" that rice is almost universally bought and sold wholesale, and by its submultiple measures retail. The table of measures most frequently used is : 2 lamè $=\mathrm{I}$ zalè ; 2 zalè $=\mathrm{I}$ hkwet ; 2 hkwet $=\mathrm{I}$ pyi or byi (or with the initial particle ta-ta-byi, whence "tubby"); 2 pyi=I sayat; 2 sayat =I seik; 2 seik $=\mathrm{I}$ hkwe; and 2 hkwe $=\mathrm{I}$ tin or basket. It is an interesting comment on the desire for a standard measure that the tin of "Milkmaid" brand condensed milk has become universally recognised as representing one lamè ; the Nestlé's tin as one zalè, and the tin containing preserved lichis as $3 \frac{1}{2}$ lamè. In origin the lamè is said to have been two handfuls, and the basket to have come into existence as being the amount of unhusked rice a man could conveniently carry at one time. The Burmese Government appears to have made some attempt at standardising it, and the British Government has more or less recognised as the standard basket one containing 9 gallons, other baskets being defined in Government reports in terms thereof. The baskets in ordinary use throughout the country vary a good deal, being usually somewhat smaller than 9 gallons. Most, however, contain between 8 and 9 gallons. The basket used by the rice-millers of Rangoon, Bassein, and Moulmein is as a rule a cylindrical wooden vessel, $24 \frac{1}{2}$ in. or $25 \mathrm{in}$. in height and $I_{4} \frac{1}{2}$ in. or $I_{5}$ in. in diameter. One of these measures is taken to measure a consignment of paddy, and every now and then a basket is weighed-usually 5 or 6 per 10,000. The price is fixed at so much per roo baskets of $46 \mathrm{lb}$. with the proviso that $2 \frac{1}{2}$ per cent. more be paid for every pound the average basket weighs in excess of 46 , while for every pound it weighs less 2 per cent. is deducted. For other produce for export, baskets containing definite weights are used, and trade in them is really by weight. But rural trade is almost entirely by measure.

There are practically no true liquid measures anywhere; occasionally one of the dry measures will be used, but the usual way of selling liquids is by weight, a measure containing a definite weight of the specific liquid for which it is used being frequently used for convenience.

We thus find that throughout the country, with the exception of Burma and to a less extent of Madras (here only as regards weights below the tola), the tola of I80 grains or the weight of the rupee is a universally recognised unit, and to an almost equal extent the "railway" seer of 80 such tolas is at least known and over a large extent of the country actually used. The identity of the weight of this tola and of the rupee is a most important point to remember, as it makes it almost compulsory to change the weight of that coin if any system not based on this tola be introduced. This is a proceeding very liable to be viewed with great suspicion by the less educated portion of the community. For a measure of length the British yard is almost universally known and very widely used. As a measure of area the acre is fast becoming the only really definite one. Measures of capacity are various, but dependent on measures of weight.

Accordingly the majority of the Weights and Measures Committee recommended the adoption of the " railway " seer of 80 tolas (each of r 80 grains), the British yard and the acre as fundamental units, and suggested the standardisation of suitable measures of capacity at the nearest suitable multiple of the bulk of $x_{4}^{1}$ seers of water, this being approximately equivalent to the bulk of a seer of wheat. This conclusion, negativing any approximation to a decimal system, was certainly viewed with regret by myself, but the binary system and the rupee-tola unit are so firmly rooted in the country that it seemed inadvisable to attempt to change a method which was at least equally good for the ordinary transactions of everyday life for one the advantages of which are apparent mainly in foreign trade. The fact that practically no progress towards adopting the metric system in England has been made (vide NATURE', vol. IIO, p. 29) is of considerable interest in this connexion, for when such is the case in a highly educated and intensely commercial country, where the proportion of foreign trade is probably higher than anywhere in the world, would it have been justifiable to recommend the compulsory adoption of the metric-or, in fact, of any decimal-system for India?

\section{School Instruction in Botany. ${ }^{1}$}

I $T$ is, we believe, a misfortune that so large a proportion of teachers of botany in schools know little practically of the cultivation of plants. It is, indeed, not unusual for simple laboratory experiments involving the use of growing seedlings and plants to come to an untimely end owing to lack of precautions which would be observed by every practical gardener. The uncertainty of success of even simple experiments in such unskilled hands is no doubt in part responsible for the fact that school botany is still so largely concerned with

1 The Botany Gardens of the James Allen's Girls' School, Dulwich. Board of Education. Educational Pamphlet No. 4r. Price 2s. taxonomy-which only the trained botanist can appreciate fully-and so little with those fundamental aspects of plant biology which should be of interest to all.

A general understanding of the significance of green plants in relation to the food problem, of the conditions controlling the growing of crops, and of the differences between such " artificial "vegetation and the natural vegetation of the countryside, with similar matters of fundamental importance, should be as much a part of general educational equipment as is the knowledge that the earth revolves round the sun, or the ability to use decimal notation.

NO. 2757 , VOL. IIO] 